\title{
Performance evaluation of lateral canopy shakers with catch frame for continuous harvesting of oranges for juice industry
}

\author{
Rafael R. Sola-Guirado, Sergio Castro-Garcia*, Gregorio L. Blanco-Roldán, \\ Jesús A. Gil-Ribes, Emilio J. González-Sánchez \\ (Universidad de Córdoba, Departamento de Ingeniería Rural, E.T.S.I. Agronómica y de Montes, Campus de Rabanales, \\ Ctra. Nacional IV Km 396, Cordoba, Spain)
}

\begin{abstract}
Citrus is mainly oriented to fresh consumption, and harvesting is usually performed manually. However, the high cost of harvesting and the low availability of labour can compromise the profitability of the crop when it is destined to juice industry. The development of citrus mechanical harvesting for industrial processing is conditioned to reach a high fruit removal efficiency, with a reduced damage to both fruit and trees. The current machines available are very large, requiring extensive plantations with long rows of trees to be efficient. In this study, two lateral canopy shakers equipped with a catch frame were evaluated to harvest independently both sides of the hedge on intensive citrus plantations with the main objective of determining their performance and feasibility. The lateral canopy shakers tested were three tractor-drawn machines, one commercial machine and two prototypes. The tested machines reached a mean value of $78 \%$ of fruit removal. Besides, the prototypes, equipped with a catch frame, were able to recover a mean value of $70 \%$ of yield. Although the results were promising, for achieving an efficient result, the application of this harvesting technology still requires a process of improvement, and the adaptation of both the machine and the plantation. The machines should reduce the amount of post-harvest ground fruit $(5.9 \%-10.4 \%)$. Tree damages generated by the contact of the catch frame with the trunk and the metal rods with main branches were the most relevant. Therefore, it is still necessary to increase the ground speed of the machinery and improving the design of the rods, regulating the rod penetrating deep in the canopy to improve the fruit recovery and limit the damage caused to the trees.
\end{abstract}

Keywords: harvester, mechanical harvesting, fruit removal, tree damage, Citrus sinensis L. Osbeck DOI: $10.25165 /$ j.ijabe. 20201303.4998

Citation: Sola-Guirado R R, Castro-Garcia S, Blanco-Roldán G L, Gil-Ribes J A, González-Sánchez E J. Performance evaluation of lateral canopy shakers with catch frame for continuous harvesting of oranges for juice industry. Int $\mathbf{J}$ Agric \& Biol Eng, 2020; 13(3): 88-93.

\section{Introduction}

The world production of citrus is around 128 million $t^{[1]}$. Among the main producing areas are China (26.3\%), the Mediterranean basin (20.3\%), Brazil (13.3\%) and USA (6.3\%). Currently, about $20 \%$ of citrus production is dedicated to industrial transformation. However, citrus orchards are primarily oriented for the fresh market, although fruit production for industrial transformation increase interest when fruit price is low, and farmer's profitability is compromised due to high production costs and labour availability.

Citrus harvesting is mainly performed by hand, with workers equipped with ladders, scissors and containers. Overall, harvest is

Received date: 2019-02-21 Accepted date: 2019-10-16

Biographies: Rafael R. Sola-Guirado, Assistant Professor, research interests: agricultural mechanization and automation, Email: ir2sogur@uco.es; Gregorio L. Blanco-Roldán, Associate Professor, research interests: agricultural mechanization, Email: ir3blrog@uco.es; Jesús A. Gil-Ribes, Professor, research interests: agricultural mechanization and conservation agriculture, Email: gilribes@uco.es; Emilio J. González-Sánchez, Assistant Professor, research interests: agricultural mechanization and conservation agriculture, Email: emilio.gonzalez@uco.es.

*Corresponding author: Sergio Castro-Garcia, Associate Professor, research interests: agricultural mechanization. Mailing address: Department of Rural Engineering, E.T.S.I. Agronómica y de Montes, Universidad de Córdoba, Campus de Rabanales, Ctra. Nacional Iva, km 396, Cordoba, Spain. Tel: +34-957218548, Email: scastro@uco.es. one of the most important expenses for farmers ${ }^{[2]}$. The manual harvesting cost range from $35 \%{ }^{[3]}$ to $50 \%{ }^{[4]}$ of the total production costs. The introduction of mechanical harvesting for industrial processing could play an important role in reducing costs, improving the farm profitability and economic sustainability. Previous experiences under Florida conditions, showed that mechanical harvesting could provide a reduction of the production costs by $50 \%$ whilst increasing the labor productivity by ten times ${ }^{[5]}$. However, its implantation in the citrus sector is still reduced, due to lack of adaptation of plantations, the low harvesting efficiency and possible damage to trees ${ }^{[6]}$.

The mechanical harvesting systems based on canopy contact technology can provide a continuous harvesting process where a forced vibration is applied directly to fruitful branches to detach the fruit $^{[7]}$. In addition, the canopy shaker systems can partially regulate some of their operating parameters to be adapted to the characteristics of different tree species ${ }^{[8]}$. The introduction of these machines in the citrus sector would be facilitated if it could be used in various crops, such as olive groves ${ }^{[9,10]}$, coffee ${ }^{[11]}$ or blueberry ${ }^{[12,13]}$. Nowadays, the main criteria for the design and improvement of canopy shaker systems are minimum tree and fruit damage, with a maximum fruit removal efficiency. Both design criteria are conflicting objectives for the mechanized harvesting of fruits $^{[10,12,14,15]}$.

The current technology for canopy shaker systems is based on large and heavy machines, difficult to maneuver in small plots, which are designed mainly for manual harvesting. The 
commercial machinery available can work in two ways, either harvesting both sides of the hedge of trees simultaneously, or one side first and after, the other ${ }^{[16]}$. In the first case, the canopy shakers can detach and catch the fruit by over-the-row or tandem harvesters although it is required orchards with long rows and extensive working times to achieve high values of field machinery index ${ }^{[17]}$. In the second case, the machines are equipped with smaller lateral canopy shaker with better maneuverability that detach the fruit on the ground with require an extra operation to pick up fruit. In this last case, a catch frame could be introduced to avoid that removed fruit fell to ground and could increase the quality of harvested fruit ${ }^{[13,18,19]}$.

This work studies the possibility of using a unique canopy shaker harvester, with a reduced size, capable of detaching and catch the fruit from the tree canopy. The main objective of this work is to evaluate the performance of these machines and the feasibility to harvest citrus plantations on a wide hedge. The machines evaluated are tractor-drawn prototypes of lateral canopy shaker which can work independently throughout from each sides of the tree in intensive citrus plantations. These machines represent an advance in the available technology, and can facilitate their introduction into the citrus sector but there are several aspects that still need to be improved along with the adaptation of the future and exist orchards.

\section{Material and methods}

The mechanical harvesting tests were carried out in a sweet orange plantation (Citrus sinensis L. Osbeck cv. "Valencia") located in Cordoba, south of Spain, (Lat 37.786312, Long -5.206241). The trials were conducted on May 2016, during the harvest season when flowering was finishing, with a phenological growth stage of BBCH71-73. The field tests were carried out on two plots of trees, planted between 2004 and 2007, with trees formed in hedges of width and height which ranged between $3.5-4.5 \mathrm{~m}$. The trees were planted at an average distance of $3.5 \mathrm{~m}$ between trees, $7 \mathrm{~m}$ between rows and with a ridge of height $0.4 \mathrm{~m}$. The plots had an average tree density of 410 trees $/ \mathrm{hm}^{2}$ with a crown volume ranging between 15500 to $26000 \mathrm{~m}^{3} / \mathrm{hm}^{2}$. The test plots had an average yield value of $23000 \mathrm{~kg} / \mathrm{hm}^{2}$, with an average value of fruit detachment force of $70 \mathrm{~N}$ and fruit weights of $200 \mathrm{~g}$.

The mechanical harvesting of oranges was performed with three different tractor-draw lateral canopy shakers (Figure 1). As a reference harvesting system, a commercial lateral canopy shaker which detached the fruit and let it fall on the ground was used. Also, two prototypes of lateral canopy shakers, developed for olive trees by the University of Cordoba (UCO), were adapted to work on citrus with a catch frame to collect the detached fruits. The machines used were:

1) Oxbo 3210: commercial tractor-drawn canopy shaker without catch frame (Oxbo 3210, Byron, New York). Fruits are fallen to the ground and subsequently collected manually. The machine has one shaking head with manual or automatic approach to the tree canopy. The shaking head is composed of $12 \mathrm{rod}$ holders with free-wheeling operation and 288 metal rods with length of $1.4 \mathrm{~m}$

2) Samolive: prototype of tractor-drawn canopy shaker with catch frame developed by UCO and Moresil S.L. Fruits are detached and collected with a catch frame. The machine is based on four head, with manual or automatic approach to the tree canopy, formed by two drums, offset $180^{\circ}$, that may rotate freely and moved by eccentric masses powered each one by a motor. The shaking head is composed of 120 metal rods with length of $1.4 \mathrm{~m}$. The free end of the rod is in the vertical of the end of the catch frame.

3) Mediolive: prototype of tractor-drawn canopy shaker with catch frame developed by UCO and MaqTec Inc. Fruits are detached and collected with a catch frame. The machine has one shaking head, with a manual approach to the tree canopy, connected to three inertial masses with a rotational movement controlled by a configurable brake. The shaking head is composed of 156 nylon rods with length of $0.7 \mathrm{~m}$ (shorter than the other prototypes because of the mechanical properties of the material). The free end of the rod is in the vertical of the end of the catch frame.

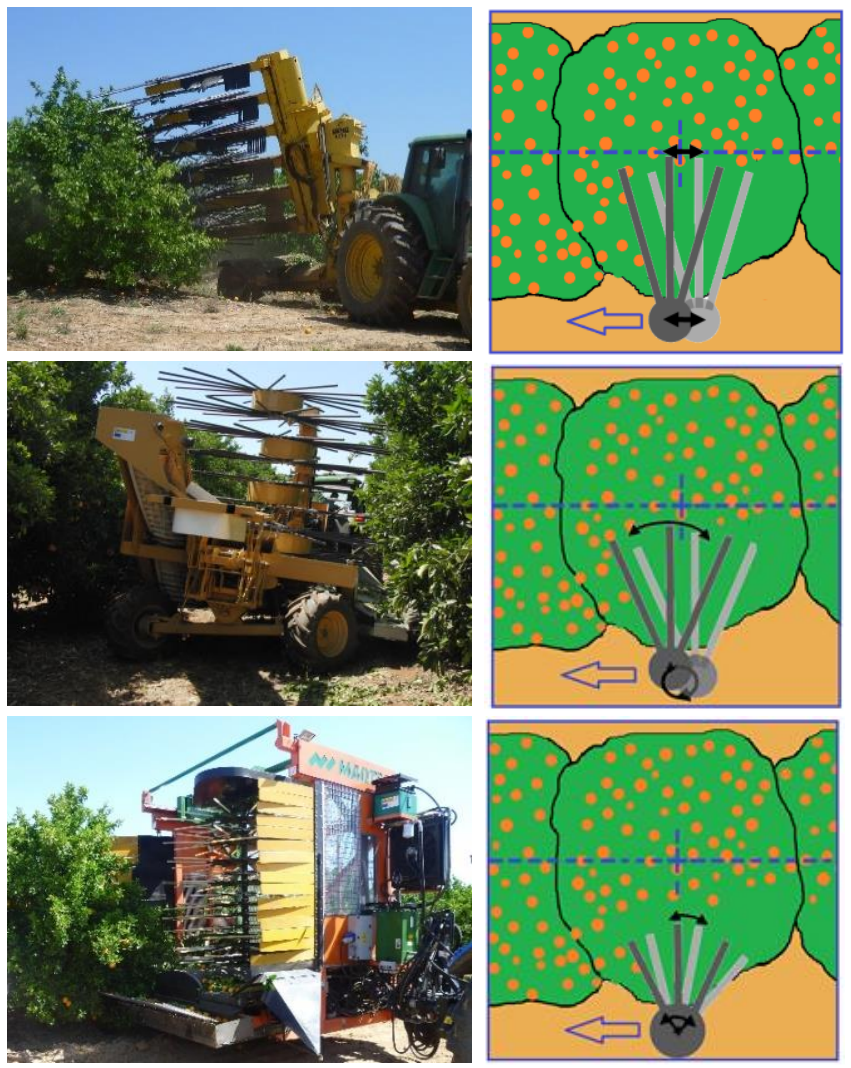

Figure 1 Tractor-drawn citrus harvesters (left) and canopy shaker mechanism descriptions (right) tested for a lateral harvesting of the trees. Oxbo 3210 (top), Samolive (center) and Mediolive (bottom)

The parameters of the vibration generated by each machine were recorded by means of a sensor accelerometer placed at the end of the rods (Figure 2). The vibration values were used to characterize the machine and allowed a previous regulation of the prototypes before the harvesting tests. A triaxial accelerometer based on MEMS sensor was used (Gulf Coast Data Concepts LLC, X200-4) with a measurement range of $\pm 200 \mathrm{~g}, 16$-bit resolution, a sensitivity of $0.06 \mathrm{~m} / \mathrm{s}^{2}$ and a sampling frequency of $400 \mathrm{~Hz}$ was used. Vibration analysis was performed using NVGate v8.0 software, using a Fast Fourier Transformation with 401 lines in a frequency range of $0-156.2 \mathrm{~Hz}$ with a $0.3905 \mathrm{~Hz}$ resolution. The resultant acceleration in the machine was calculated as the vector sum of the values along each measurement axis.

The mechanical harvesting tests were carried out, once tested and regulated the prototypes in similar trees, with 9 repetitions including 6 trees by repetition. The regulation of each machine remained constant in all repetitions. The trees were shaken on both sides of the hedge. The commercial machine was driven in a 


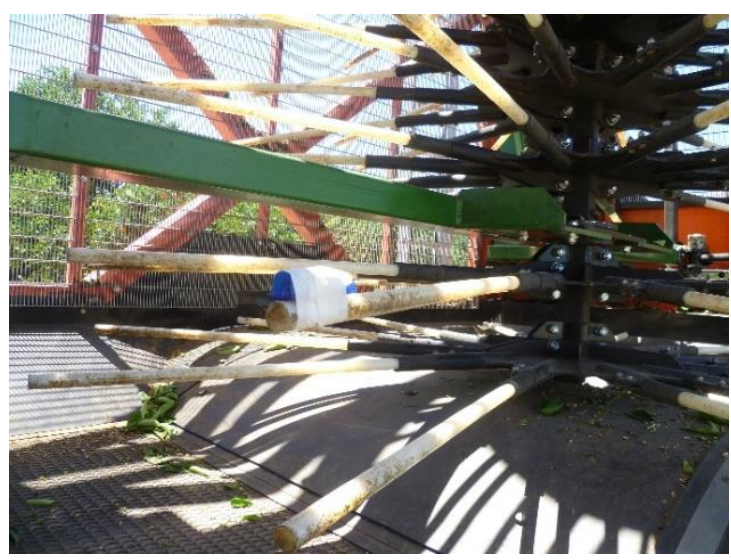

a. Mediolive prototype equipped with nylon rods

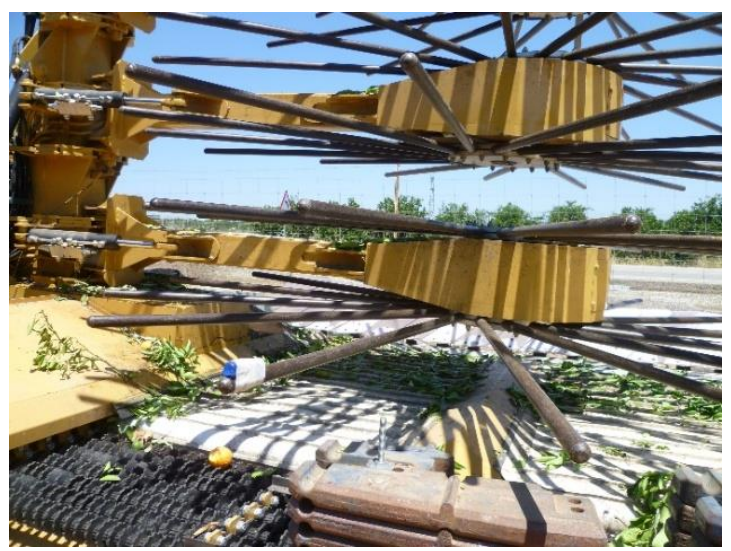

b. Samolive prototype equipped with metal rods

Figure 2 Wireless acceleration sensor located at the free end of the harvester rod

ground speed of $1.5 \mathrm{~km} / \mathrm{h}$. The both prototypes were driven slower at $1 \mathrm{~km} / \mathrm{h}$ to allow the driver a reasonable time to maintain a proper contact between the rods and the canopy tree but also between the catch frame and the trunks. All the machines were operated in the frequency range between $4-5 \mathrm{~Hz}$, ensuring that the shaking system had an adequate contact with the tree canopy. The preharvest fruit drops were a small amount and were removed before the start of the harvesting field tests. Figure 3 shows a diagram of the fruits in the tree and the determination of the harvesting parameters to characterize the mechanical harvesting process. For each test repetition, the terms listed below were determined:

1) Yield $\left(\mathrm{kg} / \mathrm{hm}^{2}\right)$ : fruit production before harvesting.

2) Fruit removal (\%): percentage of yield removed from the tree during the shaking process. Fruit remaining in canopy after the shaking process were hand harvested.

3) Fruit recovery (\%): percentage of yield removed from the tree during the shaking process and intercepted by the catch frame.

4) Post-harvest ground fruit (\%): percentage of yield removed from the tree during the shaking process and dropped to ground. The post-harvest ground fruit was divided into two parts, ground fruit dropped at same machine row and ground fruit dropped at opposite row.

5) After the mechanical harvesting process, the damages caused by the machine to the trees were evaluated, by means of the identification and visual classification of the breakage of branches, shoots and trunk bark in 3 categories (Figure 4).

6) Low tree damage: debarking or branch breakage of low importance, where the tree can easily recover.

7) Moderate tree damage: medium damage due to breakage or branch debarking in high number or extent area that affects part of the tree and could cause a yield reduction in the subsequent season.

8) Severe tree damage: grave damage to main branches or trunk that affects the tree's productivity and could affect its productive life.

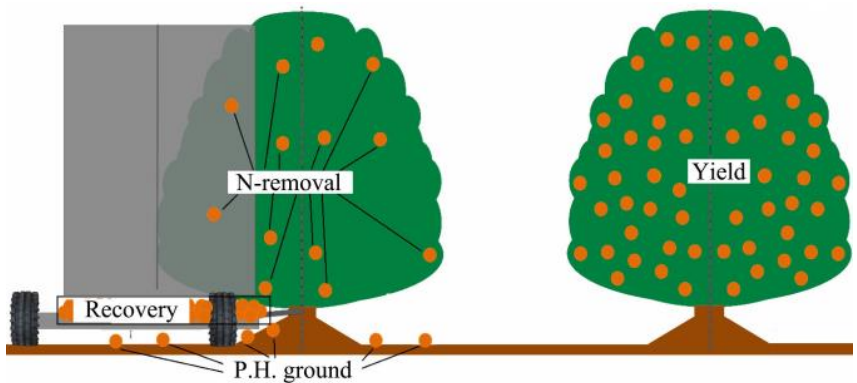

Figure 3 Harvesting parameter evaluation with lateral canopy shakers. The lateral canopy shakers require shaking both sides of the hedge to complete the harvesting process. The harvesting parameters evaluated were: (a) fruit yield, (b) fruit recovery, (c) post-harvest ground fruit at the same row and at opposite row, (d) fruit removal $=\mathrm{b}+\mathrm{c}$ and fruit non-removal $(\mathrm{a}-\mathrm{d})$
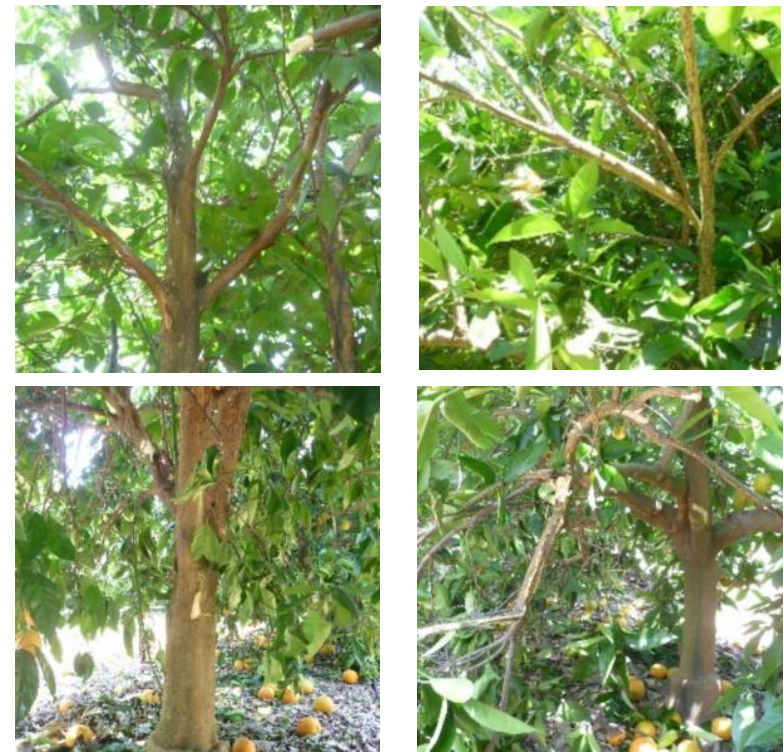

Figure 4 Tree damage classification caused by mechanical harvesting with lateral canopy shaker harvesters: low tree damage (left), moderate tree damage (central) and severe tree damage (right) 
The evaluation of the fruit damages was carried out counting the number of fruits that suffered rot in their storage after the mechanical harvesting process. For each machine, 2 samples of approximately 100 fruits each were evaluated, with 3 repetitions. The first sample consisted of detached fruit by the machine and intercepted by catch frame for prototypes, or over the ground for commercial canopy shaker. The second sample consisted of remaining fruit on the canopy after shaking process. Each sample was stored under laboratory conditions at an approximate temperature of $24^{\circ} \mathrm{C}-26^{\circ} \mathrm{C}$ and an average relative humidity between $40 \%-50 \%$, in order to speed up the rotting process and detect possible fruit damage caused by the mechanical harvesting as soon as possible. For a period of $18-20 \mathrm{~d}$, rotten fruits were removed and counted every $3-4 \mathrm{~d}$.

\section{Results and discussion}

The lateral canopy shaker harvesters reached an average fruit removal which ranged between $74.0 \%$ and $81.9 \%$ (Table 1), with not significant differences between the machines (ANOVA, $p=0.168$ ). Although the fruit removal values were high and promising, previous works in citrus show that there is room for efficiency improvements with these machines. During the 2003/04 harvest season in commercial orchards in Florida, the canopy shaker systems (Oxbo 3210 and 3220), working with Valencia variety, in planting density of $407 \mathrm{tree} / \mathrm{hm}^{2}$ and average tree height of $3.96 \mathrm{~m}$, reached average fruit removal values of $94 \%{ }^{[20]}$. Subsequently, Roka et al. ${ }^{[7]}$ showed that these machines can reach a fruit removal value of $90 \%-95 \%$ of mature fruit when an experienced operator is harvesting a continuous uniform tree canopies less than $5.5 \mathrm{~m}$ tall.

Table 1 Citrus harvesting parameter evaluation with lateral canopy shaker machines

\begin{tabular}{lccc}
\hline & Oxbo 3210 & Samolive & Mediolive \\
\hline Fruit removal $/ \%$ & $78.7 \pm 10.3 \mathrm{a}$ & $81.9 \pm 8.1 \mathrm{a}$ & $74.0 \pm 7.1 \mathrm{a}$ \\
Fruit recovery $/ \%$ & n.a. & $71.5 \pm 10.1 \mathrm{a}$ & $68.0 \pm 6.2 \mathrm{a}$ \\
Post-harvest ground fruit $1 / \%$ & n.a. & $10.4 \pm 3.8 \mathrm{~b}$ & $5.9 \pm 2.3 \mathrm{a}$ \\
Same row ${ }^{2} / \%$ & & $6.1 \pm 2.6 \mathrm{~b}$ & $3.4 \pm 1.7 \mathrm{a}$ \\
Opposite row $^{3} / \%$ & & $4.3 \pm 2.2 \mathrm{~b}$ & $2.5 \pm 0.9 \mathrm{a}$ \\
\hline
\end{tabular}

Note: Values showed are mean \pm standard deviation. Same letter in the same row shows no significantly different. First row (Tukey post-hoc test, $p<0.05$ ) and successive rows ( $\mathrm{t}-$ Student, independent sample, $p<0.05$ ).

${ }^{1}$ The pre-harvest ground fruit fallen naturally were eliminated.

${ }^{2}$ Percentage of fruit, over the yield, which was detached and not intercepted by the catch frame in the same row where the machine operated.

${ }^{3}$ Percentage of fruit, over the yield, which was detached and not intercepted by the catch frame in the opposite row where the machine operated.

The machines were able to detach almost all the fruit confined in the canopy volume in contact with rods. After the mechanical harvesting process, the fruit remaining in the canopy were concentrated mainly in the zones with difficult access to the rods, which are the interior and between canopies of the trees in same row and in lower branches. In fact, the fruit production of orange trees is $80 \%$ located in the $1 \mathrm{~m}$ from the outside of the canopy ${ }^{[21]}$ since the lighting favors fructification ${ }^{[22]}$. The different repetitions of the harvesting tests showed a positive linear correlation of yield and fruit removal (Pearson coefficient 0.404, sig. $0.089 n=19$ ) and fruit recovery (Pearson coefficient 0.563 , sig. $0.023 n=16$ ). The result obtained with these harvesting systems could improve the fruit removal value in years of higher production, since increases in yield could increase the fruit percentage accessible to rods. A similar outcome was described by Roka et al. ${ }^{[7]}$ and Liu et al. ${ }^{[23]}$, where the authors confirmed that the vibration of the canopy by rods was not transmitted efficiently to other canopy areas and, therefore, was not effective for fruit detachment. Ferguson and Castro-Garcia ${ }^{[9]}$ and Liu et al. ${ }^{[23]}$ showed that a reduction of tree canopy in table olive trees, through mechanized and manual pruning, was advisable in order to reach an efficient performance of the canopy shaker systems, because fruits were more accessible to machines.

Reducing the post-harvest ground fruit, due to mechanical harvesting with lateral canopy shakers, is an important subject for economic and quality reasons. The fruit fallen on ground implies the requirement of human labor for picking by hand. Additionally, the fruit quality can be compromised by mixing with naturally fallen fruit and by receiving a high impact due to the height of the canopy ${ }^{[18,24]}$. The prototype machines, which had catch frame, showed significant differences between mean values of post-harvest ground fruit (t-Student, independent sample, $p=$ 0.011). Both, Samolive (10.4\%) and Mediolive (5.9\%) prototypes showed a high value of post-harvest ground fruit, which requires an improvement on the machine performance in order to reduce this value. The post-harvest ground fruit in the same row could be reduced by the improvement of the catch frame, both with a larger size and avoiding rebounds of the removed fruit. It was observed that a part of the removed, but not recovery fruit, bounced inside the catch frame, powered by a sudden detachment process, falling by the lack of adequate implements between the catch frame and trunks. The falling of post-harvest ground fruit in the opposite row, ranged between $2.5 \%$ and $4.3 \%$. The removed fruit in the opposite row could be reduced by the modification of the rod penetrating deep into the canopy and the rod material. Liu et al. ${ }^{[25}$ showed that the vibration transmission along the branch was reduced $(42 \%)$, and that a rod-branch interaction at $30 \%$ at the free end of branch length could improve the fruit removal percentage. This fact is highlighted in both tested prototypes that have different rod lengths and achieved different fruit removal values. The orchard design, increasing the planting density, and a proper pruning management can reduce the internal fructification fruit in the tree canopy ${ }^{[26]}$. These proposals seem more appropriate than prolonging the rod penetration into the canopy for lateral canopy shakers. On the other hand, Liu et al. ${ }^{[23]}$ proposed replacing the nylon rod with metal rods, which could improve fruit removal whilst reducing the tree damage.

The tested shaking systems presented important differences regarding their operation and the vibration generated in the tree canopy (Table 2). The average values of vibration frequency ranged between average values of $4.1 \mathrm{~Hz}$ and $4.9 \mathrm{~Hz}$, with significant differences between them (Tukey post-hoc test, $p<0.05$ ). Oxbo 3210 and Samolive prototype were equipped with the same metal rods with length of $1.4 \mathrm{~m}$. These rods showed small amplifications of the resultant acceleration (20\%) from the drum to free end of the rod. However, Mediolive prototype was equipped with $0.7 \mathrm{~m}$ long nylon rods generated an amplification of the acceleration of the drum to the free end of the rod up to 6 times and 3 times the amplitude of movement. Pu et al. ${ }^{[6]}$ showed that both the material and the shape of the rod had an important relationship with the fruit removal and the tree damage level. The design of the rod, both in shape and material is important to find a delicate compromise between tree and fruit damage and fruit removal ${ }^{[6,11]}$.

The machine ground speed has an important implication on the overall cost of any mechanical harvesting system. However, the speed of the machines during the field tests was very low $(1 \mathrm{~km} / \mathrm{h})$. 
In similar experiences, $\mathrm{Yu}$ et al. ${ }^{[12]}$ indicated that prototypes developed for blueberry had limitations in the commercial development due to the limitation to exceed $1 \mathrm{~km} / \mathrm{h}$. As a suitable ground speed value for citrus, Shamshiri et al. ${ }^{[17]}$ reported a usual ground speed of $1.8 \mathrm{~km} / \mathrm{h}$ for canopy shakers. Although this value may be elevated to provide a required vibration time for fruit detachment (from 1.45 to $5.75 \mathrm{~s}$ ) ${ }^{[24]}$, the speed increase is favourable for the reduction of the tree damage ${ }^{[6]}$.

Table 2 Vibration parameters measured in the canopy shaker rods during harvesting process

\begin{tabular}{ccccc}
\hline Parameter & Measurement position & Oxbo 3210 & Samolive & Mediolive \\
\hline Frequency/Hz & & $4.1 \pm 0.3 \mathrm{a}$ & $4.6 \pm 0.4 \mathrm{c}$ & $4.9 \pm 0.3 \mathrm{~b}$ \\
\hline \multirow{2}{*}{$\begin{array}{c}\text { Acceleration RMS } \\
\text { in rods global } / \mathrm{m} \cdot \mathrm{s}^{-2}\end{array}$} & Free end of the rod & 48.0 & 67.5 & 161.3 \\
\hline $\begin{array}{c}\text { Displacement } \\
\text { peak-peak } / \mathrm{mm}\end{array}$ & Drum & 158.2 & 218.3 & 101.3 \\
& Free end of the rod & 212.4 & 220.1 & 313.0
\end{tabular}

Note: Values showed are mean \pm standard deviation. Same letter in the same row shows no significantly different (Tukey post-hoc test, $p<0.05$ )

Table 3 shows the damage caused to trees and fruits during mechanical harvesting with canopy shakers. In general, the damage evaluated in the tree were reduced (average value less than 4 damages per tree) and were located on the outside part of the canopy. The most common tree damages were classified as "low" and did not show significant differences between machines (Tukey post-hoc test, $p=0.141$ ). These low but frequent damages could have a limited effect on yield reduction in the subsequent season, mainly if the immature fruitlets are small and the fruit detachment force of the mature fruit is reduced with the use of an abscission agent $^{[27]}$. However, the volume generated from leaves, shoots and branches can be important for blockage in conveyor belts, and can increase transport and cleaning costs before fruit industrial $\operatorname{processing}^{[28]}$.

Table 3 Harvesting parameters with the different canopy shakers for the whole plot evaluated

\begin{tabular}{ccccc}
\hline & Parameter & Oxbo 3210 & Samolive & Mediolive \\
\hline $\begin{array}{c}\text { Tree damage } \\
\text { (\#/tree): }\end{array}$ & low & $2.5 \mathrm{a}$ & $3.2 \mathrm{a}$ & $2.5 \mathrm{a}$ \\
\multicolumn{2}{c}{ moderate } & $0.6 \mathrm{a}$ & $1.2 \mathrm{~b}$ & $0.3 \mathrm{a}$ \\
\hline Number of broken fruit (\% of removal) & 1.2 & 2.9 & 1.8 \\
\hline \multirow{2}{*}{$\begin{array}{c}\text { Rotten fruit } \\
\text { /\% }\end{array}$} & $\begin{array}{c}\text { mechanical removed } \\
\text { remaining in tree after } \\
\text { harvesting }\end{array}$ & 13.0 & 2.3 & 3.8 \\
\hline
\end{tabular}

Note: Same letter in the same row shows no significantly different (Tukey post-hoc test, $p<0.05$ )

The harvesters with longer rods presented a greater number of damages classified as 'moderate' and 'critical' than the machine with shorter rods. The longer rods had a deeper penetration into the canopy, reaching the main branches. Also, the metal rods with greater rigidity and weight than polymer rods imply a higher risk of damage to the bark. The damages classified as 'critical' were mainly caused by the contact of the catch frame with the trunks and main branches of the tree, and by the metal rods on the main branches. The number of critical damages was unacceptably high, damaging $10 \%$ of the harvested trees. This high value shows the necessary future developing works to limit and soften the contact of the machine with the tree. The reduction of the fruit and tree damages required development of the pad material on the catch frame, the rod design to reduce the potential damage to the tree ${ }^{[6]}$ and the adjustment of the rod penetration and vibration frequency during the harvesting process ${ }^{[29]}$.

The removed fruit by canopy shakers showed between 1.2 and $2.9 \%$ of fruit with external breakage. Most of this damaged fruit was post-harvest ground fruit, mainly due to the machine wheel, and the rod impact that launched the fruit out of catch frame. The reduction of the percentage of damaged fruit is an important objective, even if the fruit goes for the juice industry. The machine improvement should be focused on adapting the catch frames, in order to reduce the post-harvest ground fruit ${ }^{[30]}$ and the implementation of material pad and wheel cleaning systems.

The evaluation of the rotten fruits after the mechanical harvesting showed less amount of damaged fruit with machines equipped with a catch frame $(2.3 \%$ and $3.8 \%)$, rather than machines with ground fruit removal $(13.0 \%)$. The catch frame reduced the height of fruit fallen from the tree, and therefore the impact energy of the fruits. Besides, if pad materials were used it would help to preserve the quality of harvested fruit ${ }^{[18]}$. On the other hand, the remaining fruit on the canopy after mechanical harvesting presented the higher values of rotten fruits, peaking at $19.2 \%$. These fruits were exposed to high levels of impacts that did not reach the fruit detachment process. However, their quantity was reduced and require a prompt subsequent collection.

\section{Conclusions}

The use of lateral canopy shaker systems to harvest intensive citrus orchards for juice showed promising results. Despite using only one lateral machine, harvesting independently both sides of the hedge, the prototypes reached a mean fruit removal of $78 \%$. In addition, the machines equipped with catch frame were able to recover $70 \%$ of the fruit production. However, the development of lateral canopy shaker harvester requires the adaptation of catch frame and rods to reduce the post-harvest ground fruit (5.9\%-10.4\%), and limiting the damage caused to tree. The damages caused both to fruit and tree have been shown as two important parameters in the design and use of these machines during the harvesting of oranges for juice.

\section{Acknowledgements}

This work has been supported by research project RTA2014-00025-C05-03 from the National Institute for Agricultural and Food Research and Technology (INIA, Spain) financed by FEDER funds. Authors wish to acknowledge the support of Spanish Ministry of Economy and Competitiveness (Pre-commercial public procurement Mecaolivar), Cítricos del Andévalo S.L. for the support and funding received for the adaptation of the prototypes and Moresil S.L. and Maqtec Inc. for the developed prototypes.

\section{[References]}

[1] FAOSTAT. Citrus fruit fresh and processed. Statistical bulletin. 2016 http://www.fao.org/economic/est/est-commodities/citricos/es/. Accessed on [2019-02-10]

[2] Brotons-Martínez J M, Martin-Gorriz B, Torregrosa A, Porras I. Economic evaluation of mechanical harvesting of lemons. Outlook Agr, 2018; 47: 44-50.

[3] Junta de Andalucía. Observatorio de precios y mercados. Costes medios de producción. Campaña 2016-17 [Average production costs. 2016-17 season]. $2017 . \quad \mathrm{http}: / / \mathrm{www} . j u n t a d e a n d a l u c i a . e s /$ agriculturaypesca/observatorio. Accessed on [2019-02-10]

[4] Sanders K F. Orange harvesting systems review. Biosyst Eng, 2005; 90 $115-125$.

[5] Roka F M, Hyman B R. Mechanical harvesting of sweet oranges for juice processing. Acta Horticulturae, 2012; 965: 241-244. 
[6] Pu Y J, Toudeshki A, Ehsani R, Yang F, Abdulridha J. Selection and experimental evaluation of shaking rods of canopy shaker to reduce tree damage for citrus mechanical harvesting. Int J Agr Biol Eng, 2018; 11(2): $48-54$.

[7] Roka F M, Ehsani R J, Futch S H, Hyman B R. Citrus mechanical harvesting systems - Continuous canopy shakers. Florida: Food and economic Resources Department, UF/IFAS Extension, 2014.

[8] Sola-Guirado R R, Jimenez-Jimenez F, Blanco-Roldan G L, Castro-Garcia S, Castillo-Ruiz F J, Gil Ribes J A. Vibration parameters assessment to develop a continuous lateral canopy shaker for mechanical harvesting of traditional olive trees. Span J Agric Res, 2016; 14(2): e0204.

[9] Ferguson L, Castro Garcia S. Transformation of an ancient crop: Preparing California 'Manzanillo' table olives for mechanical harvesting. Horttechnology, 2014; 24: 274-280.

[10] Sola-Guirado R R, Castro-García S, Blanco-Roldán G L, Jiménez-Jiménez F, Castillo-Ruiz F J, Gil-Ribes J A. Traditional olive tree response to oil olive harvesting technologies. Biosyst Eng, 2014; 118: 186-193.

[11] Ferreira Júnior L G, da Silva F M, Ferreira D D, Sales R S. Recommendation for mechanical harvesting of coffee based on vibration behavior settings rods harvesters. Cienc Rural, 2016; 46: 273-278.

[12] Yu P, Li C, Takeda F, Krewer G, Rains G, Hamrita T. Measurement of mechanical impacts created by rotary, slapper, and sway blueberry mechanical harvesters. Comput Electron Agr, 2014; 101: 84-92.

[13] DeVetter L W, Yang W Q, Takeda F, Korthuis S, Li C. Modified over-the-row machine harvesters to improve northern highbush blueberry fresh fruit quality. Agriculture (Switzerland), 2019; 9: 13.

[14] Gupta S K, Ehsani R, Kim N H. Optimization of a citrus canopy shaker harvesting system: Mechanistic tree damage and fruit detachment models. Trans ASABE, 2016; 59: 761-776.

[15] Zhou J, He L, Zhang Q, Du X, Chen D, Karkee M. Evaluation of the influence of shaking frequency and duration in mechanical harvesting of sweet cherry. Appl Eng Agr, 2013; 29: 607-612.

[16] Savary S K J U, Ehsani R, Schueller J K, Rajaraman B P. Simulation study of citrus tree canopy motion during harvesting using a canopy shaker. Trans ASABE, 2010; 53: 1373-1381.

[17] Shamshiri R, Ehsani R, Maja J M, Roka F M. Determining machine efficiency parameters for a citrus canopy shaker using yield monitor data. Appl Eng Agr, 2013; 29: 33-41.

[18] Ortiz C, Blasco J, Balasch S, Torregrosa A. Shock absorbing surfaces for collecting fruit during the mechanical harvesting of citrus. Biosyst Eng, 2011; 110: 2-9.

[19] He L, Fu H, Sun D, Karkee M, Zhang Q. Shake-And-catch harvesting for fresh market apples in trellis-Trained trees. Trans ASABE, 2017; 60: 353-360.

[20] Roka F M, Hyman B R. Mechanical harvesting of sweet oranges for juice processing. Acta Hortic, 2012; 965: 241-244.

[21] Juste F, Fornes I, Castillo S. Tree configuration and fruit distribution of citrus for mechanical harvesting. Fruit, Nut and Vegetable Production Engineering, 1993; 17-27.

[22] Ferguson J J, Wardowski W F. Factors affecting fruit quality. Citrus research and Education Center, Lake Alfred, Florida. 1988

[23] Liu T H, Ehsani R, Toudeshki A, Zou X J, Wang H J. Experimental study of vibrational acceleration spread and comparison using three citrus canopy shaker shaking tines. Shock Vib, 2017. ID 9827926.

[24] Castro-Garcia S, Sola-Guirado R R, Gil-Ribes J A.. Vibration analysis of the fruit detachment process in late-season 'Valencia' orange with canopy shaker technology. Biosyst Eng, 2018; 170: 130-137.

[25] Liu T H, Luo G, Ehsani R, Toudeshki A, Zou X J, Wang H J. Simulation study on the effects of tine-shaking frequency and penetrating depth on fruit detachment for citrus canopy-shaker harvesting. Comput Electron Agr, 2018; 148: 54-62.

[26] Whitney J D, Elezaby A, Castle W S, Wheaton T A, Littell R C. Citrus tree spacing effects on soil water use, root density, and fruit yield. Trans ASAE, 1991; 34: 129-134.

[27] Roka F M, Burns J K, Buker R S. Mechanical harvesting without abscission agents-yield impacts on late season 'Valencia' oranges. Proc Fl State Hort Soc, 2005; 118: 25-27.

[28] Spann T M, Danyluk M D. Mechanical harvesting increases leaf and stem debris in loads of mechanically harvested citrus fruit. HortScience, 2010; 45: 1297-1300.

[29] Liu T H, Luo G, Ehsani R, Toudeshki A, Zou X J, Wang H J. Simulation study on the effects of tine-shaking frequency and penetrating depth on fruit detachment for citrus canopy-shaker harvesting. Comput Electron Agr, 2018; 148: 54-62.

[30] Sola-Guirado R R, Blanco-Roldan G L, Castro-Garcia S, Castillo-Ruiz F J, Gil-Ribes J A. An innovative circular path harvester for mechanical harvesting of irregular, large-canopy olive trees. Int J Agric Biol Eng, 2018; 11(3): 86-93. 